\title{
Aortic coarctation repaired within the first year of life: an 11 year review
}

\author{
Elina Ligere*, Aris Lacis*, Lauris Smits*, Valts Ozolins*, Normunds Sikora*, Inta Bergmane*, Inguna Lubaua*, Inga \\ Lace*, L. Feldmane** \\ *University Hospital for Children, Department for Pediatric cardiology and Cardiac Surgery, Riga, Latvia \\ **Riga Stradins University, Department of Pathology, Latvia
}

\begin{abstract}
Summary
Introduction. Congenital heart diseases (CHD) affect 8-12 per 1000 live-born infants and it is one of the most common and serious congenital anomalies, aortic coarctation ( $\mathrm{AoC}$ ) accounts for $6-10 \%$ of all the congenital heart diseases, and if not diagnosed early in life it can result in severe morbidity and mortality $(3,9,13,11)$.

Aim of the study. The aim of the study was to analyze the epidemiology of AoCo in newborn in Latvia, to evaluate a single centre 11 year experience with children who underwent AoCo repair in our institution within the first year of life, to define morbidity, mortality,
\end{abstract} risk factors, short and long term results.

Materials and methods. The study was approved by the committee of ethics of the university hospital for children. Retrospective and prospective study/follow-up of all (74) patients younger than 12 months undergone native coarctation repair in our institution between January1, 2000 and December 31, 2010.

Results. The prevalence of the coarctation of the aorta in Latvia was 3.43+/-1.2 per 10000 life born infants. Seventy-four neonates and infants were analyzed: 44 boys (59\%) and 30 girls (41\%). Median age at the time of primary surgical correction was $47.3+/-58$ days, medium weight $4.2+/-1.6 \mathrm{~kg}$. Prostoglandin E1 was used in $62 \%$, inotropic stimulation in $20 \%$ of cases, assisted ventilation in $18 \%$. According to the anatomy of the congenital heart disease patients constituted group I- the patients with simple coarctation with and without atrial septal defect (ASD) in 57\%, group II -patients with coarctation and ventricular septal defect (VSD) 23\%, group III- complex coarctation $20 \%$. The infantile juxtaductal AoCo with isthmus hypoplasia was detected in $83 \%(n=62)$, postductal AoCo in $4 \%(n=3)$ and juxtaductal membrane in $12 \%(n=9)$, hypoplasia of the aortic arch in $16 \%(n=12)$. The techniques for primary repair included the resection with simple anastomosis end-to-end (ETE) in $26 \%(\mathrm{n}=19)$, subclvian flap aortoplasty(SFA) in $65 \%(\mathrm{n}=48)$ and extended anastomosis end-to-end (eETE) in $8 \%(n=6)$, primary balloon angioplasty in 1 case. There were 5 cases $(6,8 \%)$ of early postoperative death and 9 cases of later death. Recoarctation occurred in 14 patients (23\%), all underwent balloon angioplasty with no significant residual gradient, and there was no mortality or complications after reinterventions.

Conclusions. The surgical correction of the AoCo remains gold standard for neonates and small infants. There were no statistically significant differences between the incidences of recoarctation dependent on the method of primary surgical correction. The incidence of recoarctation in cases of primary surgical correction early in life remains comparatively high. Baloon angioplasty is a method of choice in cases of recoarctation, it is safe and effective with low incidence of persistent coarctation. Mortality is most importantly influenced by preoperative status, the severity of associated anomalies, surgical outcomes, perioperative intensive treatment.

Key words: aortic coarctation, congenital heart disease.

\section{INTRODUCTION}

Congenital heart diseases (CHD) affect 8-12 per 1000 live-born infants and it is one of the most common and serious congenital anomalies. Approximately one quarter of these children will have critical CHD which requires surgery or catheter intervention in the first year of life $(3,6)$. The incidence of AoCo is approximately $36(29-49) / 100000$ infants. AoCo accounts for 6-10\% of all the congenital heart diseases (3, 9, 11, and 13). According to the data from European surveillance of congenital anomalies the prevalence of AoCo excluding chromosomal anomalies during years from 2005 to 2009 in summary from all the registries ranged 2.49-3.01 per 10000 live births (16). There is a prevalence of infantile type coarctation with variable degree of the hypoplasia of aortic arch in infants. It leads to the development of severe left heart failure after the closure of the ductus arteriosus with subsequent circulatory shock, acidosis, renal insufficiency and death if left untreated. Ductal dependent coarctation may require early surgical intervention. If not diagnosed early in life, it can result in severe morbidity and mortality. In approximately $64 \%$ of the infants with AoCo it manifests as a leading CHD soon after the birth (14). Due to different anatomy and possible associated anomalies, there are several methods of surgical correction of the disease. The surgical correction of the coarctation of the aorta is the standard method in neonates and infants (surgical techniques used are anastomosis end-to-end (ETE), subclavian flap angioplasty (SFA) and extended end-to-end anastomosis (eETE)) $(2,3,7,9)$. The results of primary balloon angioplasty are debatable in early age and more associated with the risk of aneurism formation, recoarctation and possible injury of femoral arteries and 
sub sequent stenosis of femoral arteries. There is high incidence of recoarctation - up to $20-40 \%$ in cases of coarctation repaired within the first year of life with the need for reinterventions- balloon angioplasty of recoarctation site. Coarctation of the aorta is associated with increased risk of arterial hypertension in further life despite successful repair and shortened life expectancy $(1,8)$. According to the literature, an early correction of the coarctation preserves the vessels of the postcoarctation zone from structural changes but the precoarctation zone remains structurally changed with the thickened intima and media as well as increased amount of collagen and elastin. Complications such as recoarctation or secondary hypertension, probably related to the loss of arterial elasticity, frequently occur after aortic coarctation surgery $(1,15)$.

\section{AIM OF THE STUDY}

Aim of the study was to explore the epidemiology of the coarctation of the aorta in newborn infants in Latvia. To analyze all the cases of aortic coarctations diagnosed and operated in our clinics within the first year of life in the period of time from January 1,2000- December 31,2010 to evaluate the risk factors for recoarctation, morbidity, mortality, short and long term results and the factors affecting the outcomes.

\section{MATERIALS AND METHODS}

The study was approved by the committee of ethics of the university hospital for children. The study was designed as a single-centre, clinical, retrospective and observational trial. The analysis of the medical records, echocardiographies, angiographies of all the neonates and infants in the age group up to twelve months diagnosed AoCo and undergone surgical and interventional correction of the coarctation in our institution between January 1, 2000 and December 31, 2010 was carried out. To analyze the epidemiology of AoCo in newborn infants in Latvia we analyzed and compared the data of all the neonates and infants up to the age of 12 months treated in our institution with the diagnosis of AoCo in the periods of time from January 1, 2000-December 31, 2004 and the period of time from January 1, 2005-December 31, 2010 in correlation to the birth rates in our country within these years. The patients were divided into 3 groups according to additional cardio-vascular diagnosis: group I- the patients with simple AoCo with and without ASD, group II -patients with AoCo and VSD, group III- complex coarctation (AoCo in combination with different intracardiac lesions). The follow up of the patients lasting 13-124 months was carried out (mean follow up time 66, 32+/34 months (median 59, 5, mode 52 months). For the data storing and processing the Microsoft Office Excel 2003 program was used. Statistical analysis was performed with SPSS 16. The anthropometric and clinical characteristics were summarized as means and standard deviations and as a percentage of the group for categorical variables. Pearson's chi-square test and Fishers exact tests were used to compare the groups of patients. The $p$ value $<0.05$ was considered statistically significant. Correlations were calculated by Spearman's rank correlation coefficient.

\section{RESULTS}

Our institution-the clinic for pediatric cardiology and cardiac surgery of the University Hospital for Children in Riga is the only institution in our country where congenital heart diseases in pediatric patients are treated so our data represent the overall data of the population of our country. The birth rates in our country within the years 2000-2010 were 21 197+/-1212 life born infants per year (49), the prevalence of the AoCo was 3.43+/1.2 per 10000 life born infants ( in the period of time from 2000-2004 it was $2.56+/-0.86$, but in the period of time from 2005-2010 4.1+/-1.1 per 10000 life born infants).

74 neonates and infants were enrolled in the study group (figure 1.). The patients with hypoplastic left heart syndrome were excluded from the study group. There were 44 boys (59\%) and 30 girls (41\%), 59\% $(n=44)$ of all the patients were newborns. Median age at the time of primary surgical correction was $47.3+/-58$ days (in the period of time from year 2000-year 2004 it was $68.7+/-67.3$ days, but within years 2005-2010 $37.65+/-51.6$ days, $p=0,033)$, medium weight at the time of primary correction of AoCo was $4.2+/-1.6 \mathrm{~kg}$. The indication for repair was conservatively untreatable heart insufficiency. Antenatal diagnosis was detected in $19 \%$ of the cases $(4 \%$ within the period of time form year 2000-2004, but $25 \%$ in the period of time from $2005-2010, p=0.032)$. There were 45 patients at the age group up to 2 months old $(61 \%$ ) (the patients considered to have ductus dependent AoCo) and prostoglandin El was used in $62 \%$. The babies were in need of inotropic stimulation in $20 \%$ of cases, assisted ventilation $18 \%$ and there were no statistically significant differences between the need of intensive care within the study period $(p>0.05)$. During the period of time from $2005-201064 \%(n=29)$ of the patients were sent by maternity hospitals, but $36 \%(n=16)$ were referred by general practitioner or emergency department after the discharge from the maternity hospital. There were other diagnoses instead of congenital heart disease suspected in $27 \%$ in the age group up to two months; they were septicemia, pneumonia and feeding disturbances. There was a correlation between antenatal diagnosis and concomitant intracardiac pathology observed in the group of patient up to 2 months old $(r=0,407, p=0.06$, $\mathrm{n}=45$ ).

According to the anatomy of the CHD patients constituted group I- the patients with simple corctation with and without ASD in $57 \%(n=42)$ ( $45 \%$ of newborns, but $73 \%$ of infants up to 12 months, $p=0.02)$, group II - patients with coarctation and VSD in $23 \%(n=17)$ (34\% newborns, but $7 \%$ in older infants, $p=0.02$ ), group III- complex coarctation in $20 \%(n=15)$ ( equal in both groups) (table l.). The infantile juxtaductal AoCo with isthmus hypoplasia was detected in $83 \%(n=62)$, postductal AoCo in $4 \%(n=3)$ and juxtaductal membrane 
in $12 \%(n=9)$, hypoplasia of the aortic arch (transverse arch below $-2 \mathrm{z}$ score according to patients body surface area ) in $16 \%(n=12)$. Bicuspid aortic valve was detected in only $8 \%(n=6)$ patients of the study group. Elevation of blood urea levels (median 9.82+/-2.21, normal range $2.5-6.4 \mathrm{mkmol} / \mathrm{L})$ was detected in $15 \%(\mathrm{n}=11)$ and elevated creatinine in $15 \%(n=11)$ ( medium $139,95+/$ $20.12 \mathrm{mkmol} / \mathrm{L}$, normal range $18-35 \mathrm{mkmol} / \mathrm{L}$ ) patients in the period prior to the operation.

The techniques for primary repair included the resection with ETE in $26 \%(\mathrm{n}=19), S F A$ in $65 \%(\mathrm{n}=48)$ and $e E T E$ in $8 \%(\mathrm{n}=6)$, primary balloon angioplasty in 1 patient. The intraoperatively resected segments of coarctation were sent for pathohistological examination and the characteristic changes were detected: intimal proliferation, fibroelastosis, disruption of elastic tissue, fibrointimal thickening (picture 3).

There were 5 cases $(6,8 \%)$ of early postoperative death(within 30 days following the surgery: 1 case of septicaemia and 4 cases of cardio-vascular insufficiency (all the cases were neonates) and 9 cases of later death in the study period: 1 renal insufficiency, 1 case of pulmonary hypertension and pneumonia, 2 cases of endocardial fibroelastosis, 3 cases of sudden death (no results of autopsies available), l case of severe cardiovascular insufficiency and acidosis and 1 patient died after the surgical correction of combined intracardiac lesion. No paraplegia and intracranial bleeding occurred. Kaplan-Meier survival curve for these patients is shown in figure 2. In the group of patients constituting lethal cases within the study period there were more cases of antenatal diagnosis $(\mathrm{p}=0.02)$, more frequent use of inotropes $(p=0.03)$ and assisted ventilation $(p=0.013)$, more often elevated urea levels $(p=0.028)$, hypoplastic aortic arches and concomitant intracardiac pathologies observed, but there was no correlation with the method of surgical correction observed (table 2.). There were 60 patients further followed up. Slight shortening of the left arm as the result of subclavian steal was found in 2 patients and asymmetry of palms in 1 in the group of Waldhausen operation $(7,7 \%)$. During the follow-up period recoarctation (mean pressure gradient $>20 \mathrm{mmHg}$ at rest in descending aorta in echocardiography) occurred at the age from 2 months to 18 years ( $2-96$ months, mean $38,21+/-32,8$ months) in 14 patients $(23 \%)$ (the lethal cases excluded) (in $73 \%$ these patients were primary repaired as neonates). There were no statistically significant differences between the incidence of recoarctation dependent on the method of primary surgical correction (18\% in ETE group, 26\% in SFA group and $25 \%$ in extended anastomosis group ( $p>0.05)$ (figure 3.). All of them underwent balloon angioplasty (one of the patients twice) with no significant residual gradient; one patient ( 8 years old) required also implantation of 2 stents due to recoarctation and hypoplastic transverse aortic arch. There was no mortality or complications after reinterventions. The actuarial survival curves show differences between survivals in groups I, II and III (figure 4). The patients age at the end of follow-up period was $66,32+/-34$ months (1 year lmonths-10years10months). There was a need of antihypertensive treatment in $8 \%$ of the patients without hemodinamically significant residual gradient.

\section{DISCUSSION}

Our data show that the prevalence of the AoCo does not significantly differ from the data of literature although there are differences between more recent data and the data from the first half of the last decade. AoCo still carries high mortality rates between neonates and small infants. Mortality is most importantly influenced by the preoperative status, the severity of associated intracardiac anomalies and perioperative intensive treatment. In the group of patients constituting lethal cases within the study period there were more cases of antenatal diagnosis $(\mathrm{p}=0.02)$, more frequent use of inotropes $(p=0.03)$ and assisted ventilation $(p=0.013)$, more often elevated urea levels $(\mathrm{p}=0.028)$, hypoplastic aortic arches and concomitant intracardiac pathologies observed which is consistent with the data from literature.

Prenatal diagnosis of aortic coarctation suffers from high false-negative rates at screening and poor specifity, therefore AoCo is most common duct-dependent cardiac defect missed at routine physical screening of the newborn. During the period of time from 2005-2010 $36 \%$ of the patients in the age group up to 2 months were referred by general practitioner or emergency department after the discharge from the maternity hospital and there were other diagnoses instead of congenital heart disease suspected in $27 \%$ which is indicative of the need for further education for general practitioners and pediatricians working with neonates and small infants.

The vast majority of the patients were operated by SFA (in $65 \%(n=48)$ ) but eETE in only $8 \%(n=6)$ of the cases therefore statistical comparison which technique is superior cannot be made. The coarctation repaired in neonates and small infants carries high recoarctation rate $(23 \%$ in our study, all the lethal cases excluded) which is comparable with the reports from literature and the recoarctation rates did not differ significantly between the methods. The data from literature confirm surgery as a method of choice for neonates and small infants in cases of AoCo. A limited number of studies comparing surgery and balloon dilatation showed significantly lower reintervention and complication rates after surgery than after balloon angioplasty in this age group. Baloon dilatation and/or stent implantation as a primary repair is mainly recommended for older children due to the need for frequent redilatation in growing children, high incidence of intimal proliferation in stents and potential aneurysm formation (16).

\section{CONCLUSIONS}

The surgical correction of the AoCo remains the gold standard for neonates and small infants. There were no statistically significant differences between the incidences of recoarctation dependent on the method of primary 
surgical correction. The incidence of recoarctation in cases of primary surgical correction early in life remains comparatively high. Balloon angioplasty is a method of choice in cases of recoarctation, it is considered to be safe and effective with low incidence of persistent coarctation. Mortality is most importantly influenced by preoperative status, the severity of associated anomalies, surgical outcomes, perioperative intensive treatment. The effect of scarifying left subclavian artery in neonates and small infants is debatable. There were no severe ischemic complications of the left arm and left hand connected with subclavian flap aortoplasty retrospectively.

\section{Conflict of interest: None}

\section{REFERENCES}

1. Bassareo PP, Marras AR, Manai ME, Mercurio G. The Influence of Different Surgical Approaches on Arterial Rigidity in Children After Aortic Coarctation Repair// Pediatric Cardiology; 2009; 30(4): 414-418

2. Barreiro CJ, Trevor A, Williams JA, Durr ML, Cameron DE, Vricella LA. Subclavian flap aortoplasty: still a safe, reproducible and effective treatment for infant coarctation// European Journal of Cardio-thoracic Surgery, 2007;31:649-653.

3. Chang RK, Gurvitz M, Rodriguez S. Missed diagnosis of critical congenital heart disease// Arch Pediatr Adolesc Med, 2008;162:969-974

4. de-Wahl Granelli A, Mellander M, Sandberg K, Sunnegardh J,Östman-Smith. Screening for ductdependent congenital heart disease with pulse oximetry: A critical evaluation of strategies to maximize sensitivity/l Acta Paediatrica, 2005; 94:1590-1596

5. Frúh S, Knirsh W, Dodge-Khatami A, Dave H, Pretre R, Kretschmar O. Comparison of surgical and interventional therapy of native and recurrent aortic coarctation regarding different age groups during childhood//European Journal of CardioThoracic Surgery, 201 1;39;898-904

6. Hoffman JIE, Kaplan S. The incidence of congenital heart disease// J Am Coll Cardiol, 2002;39: 1890-1900

7. Karamlou T, Bernasconi A, Jaeggi E, Alhabsan F, Williams WG, Van Arsdell GS, Coles JG, Caldarone CA. Factors associated with arch reinterventions and growth of the aortic arch after coarctation repair in neonates weighing less than $2,5 \mathrm{~kg} / /$ The Journal of Thoracic and Cardiovascular Surgery, 2009;137:1163-1167

8. Kenny D, Polson JW, Martin RP,Wilson DG, Caputo M, Cockroft JR, Paton J, Wolf AR. Surgical Approach for Aortic Coarctation Influences Arterial Compliance and Blood Pressure Control// Ann Thorac Surg, 2010;90:600-604

9. Lindinger A, Schwedler G, HenseHW. Results of PAN Study: Congenital heart defects in newborns in Germany-prevalence and association with demographic, genetic and peripartal parameters// Cardiology in the Young, 2010; 20(SuppS2):P S3

10. Mahle WT, Newburger JW, Matherne P et.al. Role of Pulse Oximetry in Examining Newborns for Congenital Heart Disease: A Scientific Statement from the AHA and AAP// Pediatrics, 2009; 124:2:823-836

11. Marek J, Fenton M, Khambadkone S. Aortic arch anomalies: Coarctation of the Aorta//In: Echocardiography in Pediatric and Congenital Heart Disease: From Fetus to Adult. Wiley-Blackwell; 2009;339-350

12. Matsui H, Mallander M, Roughton M, Jicinska H. Morphological and Physiological Predictors of Fetal Aortic Coarctation// Circulation, 2008;118; 1793-1801

13. Myung K Park, Troxler G. Pathofhysiology of Obstructive and valvular regurgitant lesions. Coarctation of the aorta //In: Pediatric Cardiology for Practitioners. 5th ed. Philadelphia: Mosby Elsevier; 2008;135-136

14. Samanek M, Voriskova M. Congenital heart disease among 815,569 children born between 1980-1990 and their 15-year survival: A prospective Bohemia survival study// Pediatr Cardiol, 1999; 20:41 1-441

15. Sehested J, Baandrup U, Mikkelsen E. Different reactivity and structure of the prestenotic and poststenotic aorta in human coarctation// Circulation, 1982; 65 : 1060-1065

16. www.eurocat_network.eu/prevdata/resultsPdf.asp $\mathrm{x}$ ?title $=\mathrm{A} 5$ \&allanom $=$ false $\delta$ allregf $=$ true 6 allrega $=\mathrm{tr}$ uefanomalies $=32 \delta \mathrm{win} x=1416 \delta \mathrm{winy}=770$ (access ed 26.04.2011)

\section{Address:}

Elina Ligere

University hospital for children

Clinic for pediatric cardiology and cardiac surgery

Vienibas gatve 45,

Riga, Latvia, LV-1004

e-mail: eteivane@inbox.lv

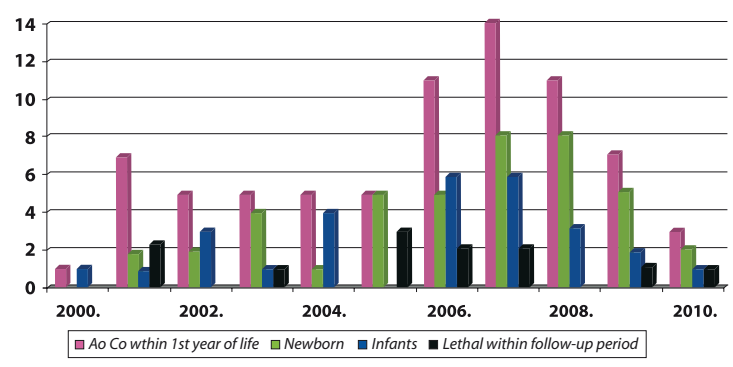

Fig. 1. Patients with AoCo corrected within the first year in life $(n=74)$. 
Table 1. The groups of patients according to concomitant intracardiac pathology.

\begin{tabular}{|c|c|c|}
\hline $\begin{array}{l}\text { Group of } \\
\text { patients }\end{array}$ & Intracardiac pathology & $\begin{array}{l}\text { Number of } \\
\text { patients }\end{array}$ \\
\hline Group I & $\begin{array}{l}\text { None(isolated } \\
\text { coarctation) }+/- \text { ASD }\end{array}$ & $42(57 \%)$ \\
\hline Group II & $\mathrm{AoCo}+\mathrm{VSD}$ & $17(23 \%)$ \\
\hline \multirow[t]{10}{*}{ Group III } & Complex coarctation: & $15(20 \%):$ \\
\hline & $\begin{array}{l}\text { Double inlet left } \\
\text { ventricle+VSD }\end{array}$ & 1 \\
\hline & $\begin{array}{l}\text { Subvalvular aortic } \\
\text { stenosis+VSD }\end{array}$ & 1 \\
\hline & Subvalvular aortic stenosis & 4 \\
\hline & Valvular aortic stenosis & 4 \\
\hline & $\begin{array}{l}\text { Supravalvular aortic } \\
\text { stenosis }\end{array}$ & 1 \\
\hline & $\begin{array}{l}\text { Mitral valve } \\
\text { insufiiciency (valve } \\
\text { pathology) }\end{array}$ & 1 \\
\hline & Mitral stenosis+VSD & 1 \\
\hline & $\begin{array}{l}\text { Atrio-ventricular septal } \\
\text { defect }\end{array}$ & 1 \\
\hline & Pulmonary stenosis+ASD & 1 \\
\hline
\end{tabular}

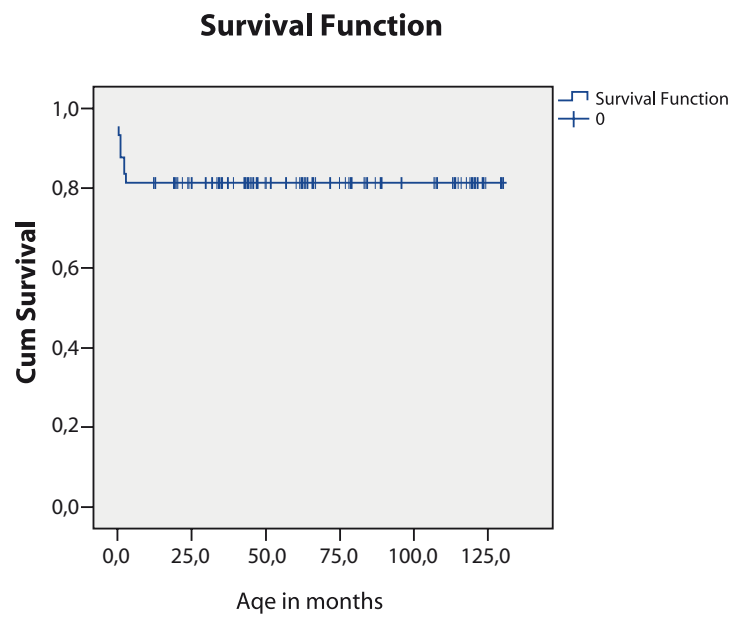

Fig. 2. Kaplan-Maier survival curve for the patients operated with AoCo within the first year of life in the priod of time from year 2000-2010.
Table 2. Factors affecting the lethal outcome.

\begin{tabular}{|c|c|c|c|c|}
\hline & & Alive & $\begin{array}{l}\text { Lethal } \\
\text { outcome } \\
\text { during } \\
\text { study } \\
\text { period }\end{array}$ & P value \\
\hline $\begin{array}{l}\text { Antenatal } \\
\text { diagnosis }\end{array}$ & $\begin{array}{l}\text { Yes } \\
\text { No }\end{array}$ & $\begin{array}{l}8(13 \%) \\
52(87 \%)\end{array}$ & $\begin{array}{l}6(43 \%) \\
8(57 \%)\end{array}$ & 0.01 \\
\hline $\begin{array}{l}\text { Use of } \\
\text { inotropes }\end{array}$ & $\begin{array}{l}\text { Yes } \\
\text { No } \\
\end{array}$ & $\begin{array}{l}9(15 \%) \\
51(85 \%) \\
\end{array}$ & $\begin{array}{l}6(43 \%) \\
8(57 \%) \\
\end{array}$ & 0.02 \\
\hline $\begin{array}{l}\text { Assisted } \\
\text { ventilation }\end{array}$ & $\begin{array}{l}\text { Yes } \\
\text { No }\end{array}$ & $\begin{array}{l}7(12 \%) \\
53(88 \%) \\
\end{array}$ & $\begin{array}{l}6(43 \%) \\
8(57 \%)\end{array}$ & 0.006 \\
\hline $\begin{array}{l}\text { Elevated } \\
\text { blood urea } \\
\text { levels } \\
\end{array}$ & $\begin{array}{l}\text { Yes } \\
\text { No } \\
\end{array}$ & $\begin{array}{l}54(90 \%) \\
6(10 \%) \\
\end{array}$ & $\begin{array}{l}9(64 \%) \\
5(36 \%) \\
\end{array}$ & 0.015 \\
\hline $\begin{array}{l}\text { Hypoplastic } \\
\text { aortic arch }\end{array}$ & $\begin{array}{l}\text { Yes } \\
\text { No }\end{array}$ & $\begin{array}{l}4(7 \%) \\
56(93 \%)\end{array}$ & $\begin{array}{l}8(57 \%) \\
6(43 \%)\end{array}$ & 0.001 \\
\hline
\end{tabular}

*Tests of significance were chi-square test and Fisher's exact test. NS-not significant, $\mathrm{P}>0.05$.

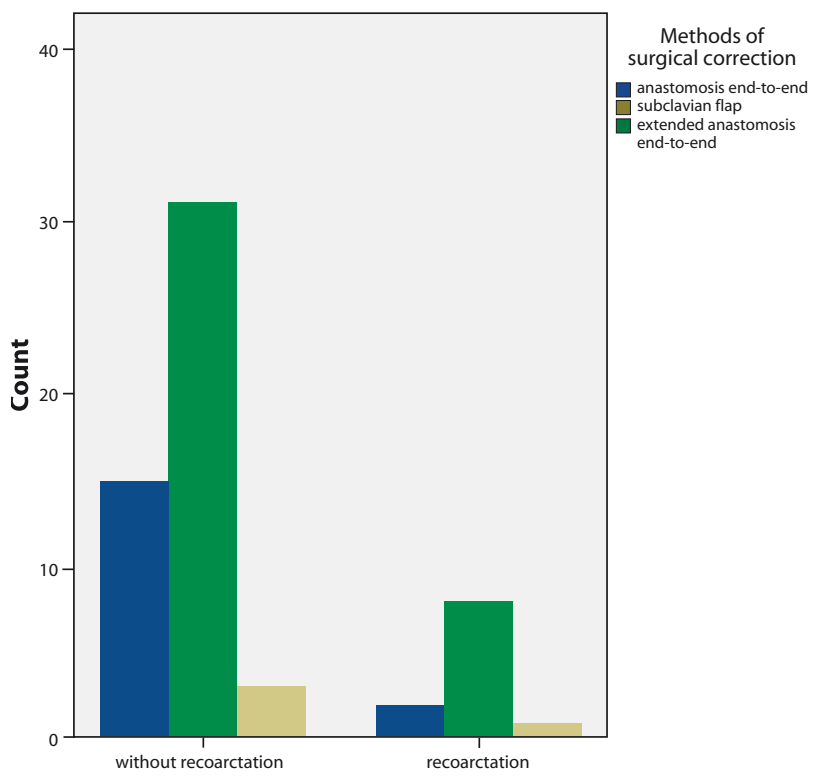

Fig. 3. Recoarctation and the method of primary surgical correction. 


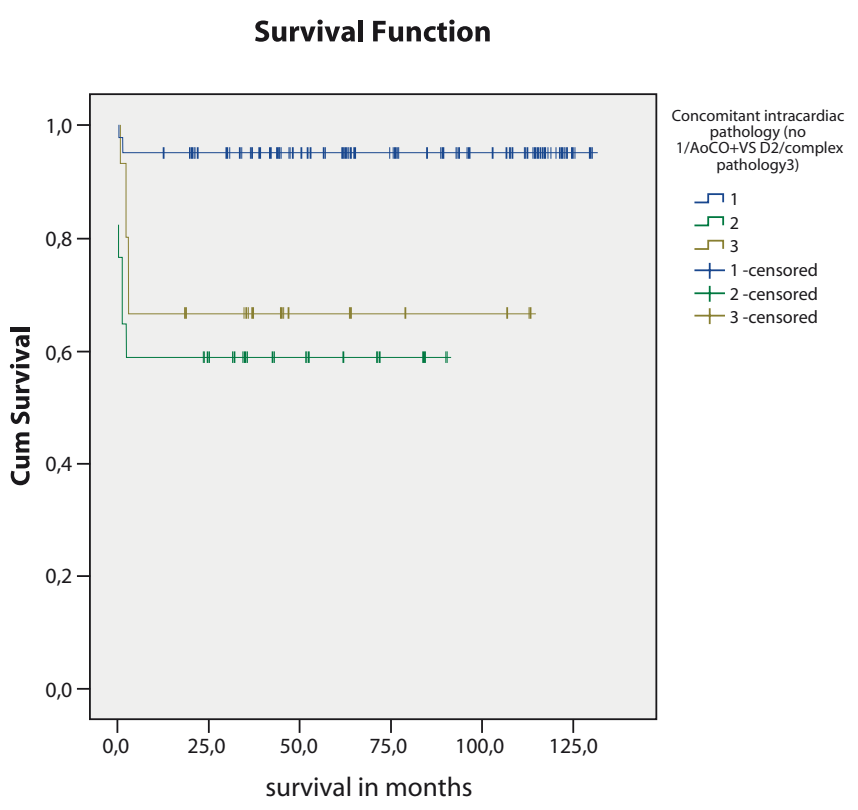

Fig. 4. Survival of patients with and without concomitant intracardiac pathology.

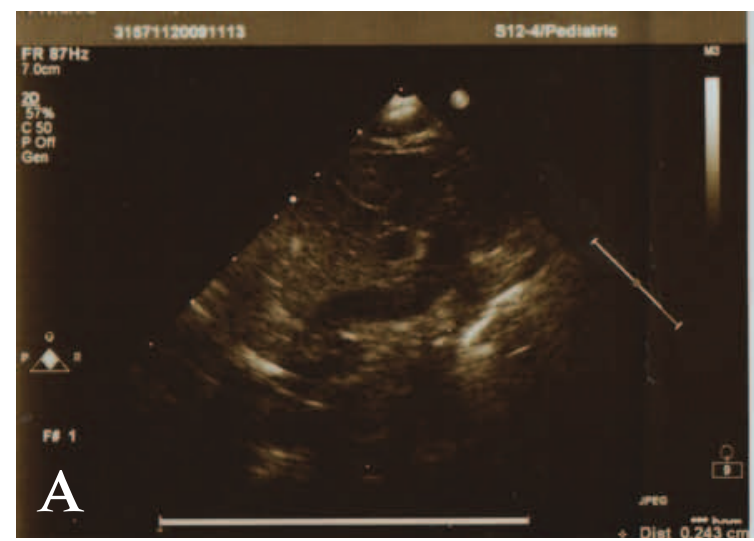

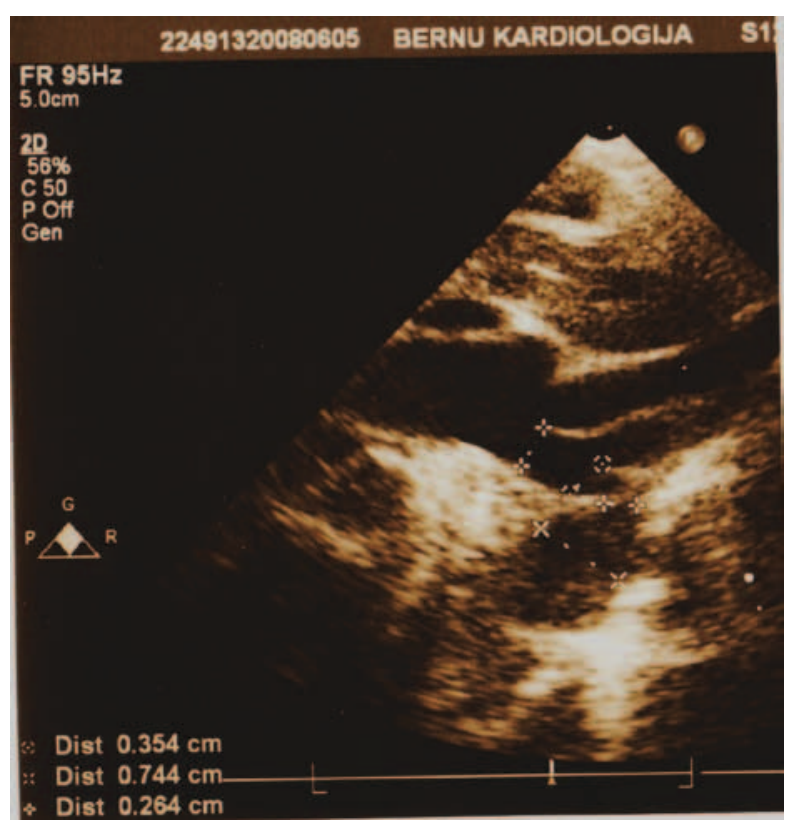

Picture 1. Echoracriography: neonate with infantile aortic coarctation and hypoplastic transverse aortic arch.

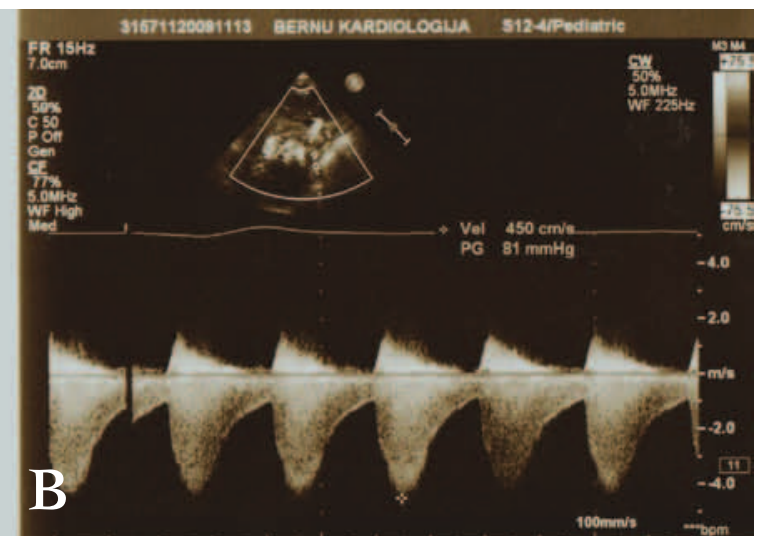

Picture 2. Echocardiography of severe AoCo( suprasternal long axis view) A, Continuous-wave Doppler through the aortic isthmus of a patient with severe AoCo (high velocity systolic amplitude(4,5m/s) with continuous antegrade flow throughout diastole $B$.

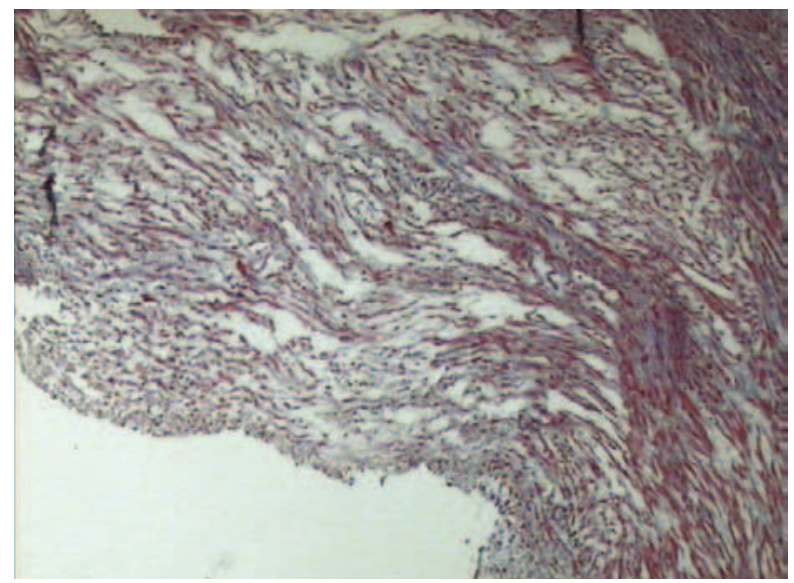

Picture 3. AoCo with fibrointimal thickening (Masson`s trichrome stain). 